\title{
Magnetic and Structural Properties of $\mathrm{NiZnFe}_{2} \mathrm{O}_{4}$ Ferrite Nanopowders Doped with $\mathrm{Cu}^{2+}$
}

\author{
Vikas J. Pissurlekar \\ Department of Chemistry, P.E.S."s. R.S.N College of Arts and Science, Ponda, Goa. - 403 401, India
}

\begin{abstract}
In this study a series of copper substituted nickel zinc ferrite nano particles with composition $\mathrm{Ni}_{0.55-\mathrm{X}} \mathrm{Cu}_{X} \mathrm{Zn}_{0.45} \mathrm{Fe}_{2} \mathrm{O}_{4}\left(\mathrm{X}_{=0.0}\right.$, $0.05,0.1,0.15)$ were prepared by precursor method. The effect of $C u$ doping on phase formation and crystal structure of sample were investigated by X-Ray diffraction (XRD), IR spectroscopy (FTIR) and scanning electron microscopy (SEM). Also the room temperature saturation magnetization of samples was studied. Hysteresis loops measurements exhibited a decrease in the saturation magnetization value (Ms) of the sample from $77.5 \mathrm{emu} / \mathrm{g}$ to $32.4 \mathrm{emu} / \mathrm{g}$. The increases in the coercivity (Hc) with increase in copper content is attributed to the bigger magneto crystalline anisotropy of $\mathrm{Cu}^{2+}$ ions compared to $\mathrm{Ni}^{2+}$ ions.
\end{abstract}

Keywords: $\mathrm{Cu}$ doped nickel-zinc ferrite, precursor, nano particles, anisotropy, magnetic properties

\section{Introduction}

Magnetic nanoparticles have been studied extensively because of their differences in their physical, magnetic and other properties compared to its bulk materials. They are also important due to their application in various fields like recording media, information storage and magneto-optical devices, as catalysts, sensors, etc. $[1,3]$. NiZnCu ferrites are also used in high-frequency devices due to their low cost, high resistivity and low eddy current losses, Nanoparticle ferrite particles, are synthesized by variety of techniques such as ceramic, co-precipitation, sol-gel technique, hydrothermal synthesis [4,7] etc. precursor method is one of the simpler method involving lesser time and requires lower processing temperature for the synthesis. In the present work nickel copper zinc ferrite nanoparticles were prepared by employing a hydrazine based ligand with metal ions in solution to obtain a precursor which decomposes automatically on drying to give nanoparticle ferrites. By doping copper for nickel and keeping fixed zinc content variations in structural and magnetic properties of nickel copper zinc ferrite on copper substitution are studied.

\section{Experimental}

Stoichiometric amounts of nickel nitrate, iron nitrate copper nitrate and zinc nitrate of analytical grade were taken as per the composition of $\mathrm{Ni}^{2+}, \mathrm{Zn}^{2+} \mathrm{Cu}^{2+}$ and $\mathrm{Fe}^{3+}$ ions for the synthesis. Nickel nitrate, copper nitrate, zinc nitrate and iron nitrate were dissolved in minimum quantity of distilled water to obtain aqueous solution of metal ions. To this solution a calculated amount of hydrazinium acetate ligand was added and it was thoroughly mixed. The mixture was then kept for drying on a hot plate. The mixture dried to a solid mass which automatically got decomposed into the powder form and were used for characterization and study of structural, electrical and magnetic properties. X-ray powder diffraction (XRD), is an instrumental technique that is used to identify the crystal structure as it is reliable for material identification. As the interatomic spacing in the crystal is of the order of $10^{-8} \mathrm{~cm}$, therefore a ray with wavelength of similar order will give rise to diffraction phenomena and it can be used to determine the phase formation of ferrite materials. The morphology analysis of the samples was carried out by scanning electron microscopy (SEM). The chemical vibrational mode of ferrite samples was studied by Fourier transform infrared spectroscopy (FTIR). The saturation magnetization measurements at room temperature of all the samples were done using Pulse Field Magnetic Hysteresis Loop Tracer. Magnetization, coercivity and remanence magnetization were calculated from the hysteresis loops.

\section{Results and Discussion}

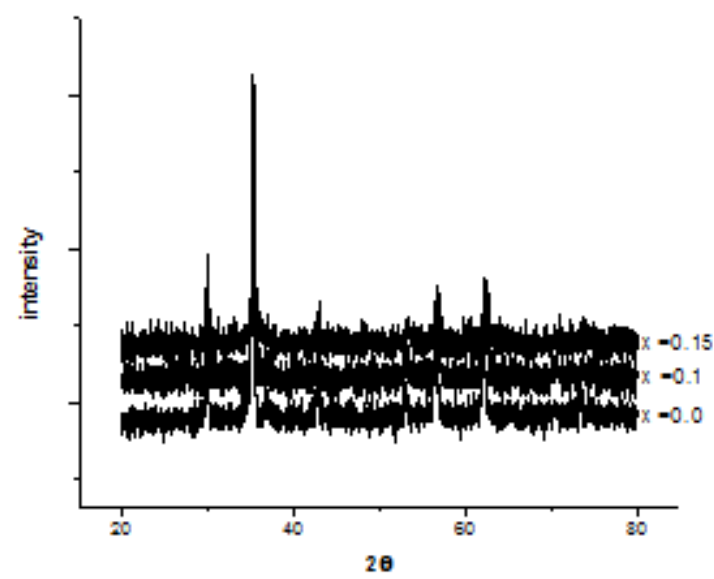

Figure 1: XRD pattern of $\mathrm{Ni}_{0.55-\mathrm{X}} \mathrm{Cu}_{\mathrm{X}} \mathrm{Zn}_{0.45} \mathrm{Fe}_{2} \mathrm{O}_{4}$

Figure 1 shows the $\mathrm{X}$-ray diffraction patterns of nanocrystalline $\mathrm{Ni}_{(0.55-\mathrm{x})} \quad \mathrm{Cu} \quad{ }_{\mathrm{x}} \mathrm{Zn}_{0.45} \mathrm{Fe}_{2} \mathrm{O}_{4}$ (where $\mathrm{x}=0.0$, $0.05,0.1,0.15)$ samples. The XRD patterns clearly indicate that, the prepared samples are exclusively of cubic spinel structure and confirm the formation of single phase ferrite.

Table 1: Variation of Lattice constant

\begin{tabular}{|c|c|}
\hline Concentration & Lattice Constant in cm \\
\hline $\mathrm{Ni}_{0.55} \mathrm{Cu}_{0} \mathrm{Zn}_{0.45} \mathrm{Fe}_{2} \mathrm{O}_{4}$ & $8.3748 \times 10^{-8}$ \\
\hline $\mathrm{Ni}_{0.5} \mathrm{Cu}_{0.05} \mathrm{Zn}_{0.45} \mathrm{Fe}_{2} \mathrm{O}_{4}$ & $8.3935 \times 10^{-8}$ \\
\hline $\mathrm{Ni}_{0.45} \mathrm{Cu}_{0.1} \mathrm{Zn}_{0.45} \mathrm{Fe}_{2} \mathrm{O}_{4}$ & $8.4080 \times 10^{-8}$ \\
\hline $\mathrm{Ni}_{0.4} \mathrm{Cu}_{0.15} \mathrm{Zn}_{0.45} \mathrm{Fe}_{2} \mathrm{O}_{4}$ & $8.4118 \times 10^{-8}$ \\
\hline
\end{tabular}

As shown in the Table 1 the values of lattice constants, $\mathrm{a}^{\text {ee }}$ calculated by using Bragges equation from the X-ray diffraction data for samples prepared from this method were 


\section{International Journal of Science and Research (IJSR) \\ ISSN (Online): 2319-7064 \\ Index Copernicus Value (2013): 6.14 | Impact Factor (2014): 5.611}

found to increase with increase in $\mathrm{Cu}$ concentration. This increase may be attributed to the larger ionic radii of $\mathrm{Cu}$ $\left(0.72 \mathrm{~A}^{0}\right)$ and $\mathrm{Zn}\left(0.82 \mathrm{~A}^{0}\right)$ relative to $\mathrm{Ni}\left(0.69 \mathrm{~A}^{0}\right)$, and is in agreement with reported values $[8,9]$.

It can be observed that the particle size increases with increase of cu content for the first two doping this may be due to increase in lattice constant strangely however for $\mathrm{x}=$ 0.15 it is found to decrease. The average crystallite size estimated from the Scherer formula is in the range of 19-39 $\mathrm{nm}$. The increase in the crystallite size is due to substitution of bigger copper $\left(0.72 \mathrm{~A}^{0}\right)$ ions for smaller nickel $\left(0.69 \mathrm{~A}^{0}\right)$ ions it indicates that, the reduction in nickel content causes the crystal growth. The surface temperature affects the molecular concentration at the surface of crystal, and hence, the crystal growth. [9].

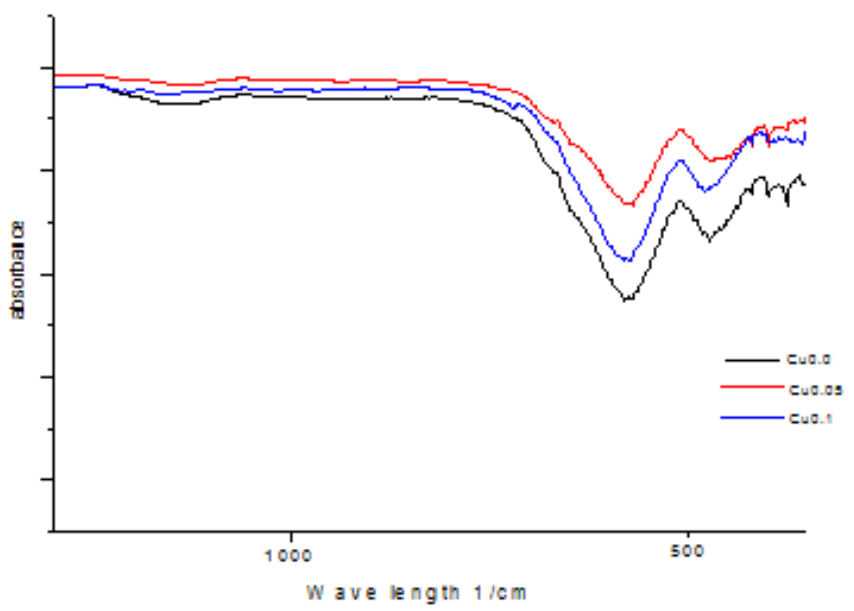

Figure 2: IR spectrum of $\mathrm{Ni}_{0.55-\mathrm{x}} \mathrm{Cu}_{\mathrm{x}} \mathrm{Zn}_{0.45} \mathrm{Fe}_{2} \mathrm{O}_{4}$

IR Spectroscopy allows us to identify the spinal structure. The three typical vibrational bonds associated with spinal structure are at (1) $600-550 \mathrm{~cm}^{-1}$ (2) $450-385 \mathrm{~cm}^{-1}$ (3) $350-$ $330 \mathrm{~cm}^{-1}$ for metal oxygen bonds. IR spectra were obtained for all samples under investigation confirming formation of spinal ferrite recorded in wavelength range $4000 \mathrm{~cm}^{-1}$ to $400 \mathrm{~cm}^{-1}$ on Shimadzu FTIR model 8900.

The IR spectrum of each sample shows two peaks, one in the range $600-550 \mathrm{~cm}^{-1}$ and the other $450-385 \mathrm{~cm}^{-1}$ corresponding to:

(1) $\mathrm{Me}_{\mathrm{T}}-\mathrm{O}-\mathrm{Me}_{\mathrm{O}}$ stretching vibration $600-550 \mathrm{~cm}^{-1}$

(2) $\mathrm{Me}_{\mathrm{O}} \leftrightarrow \mathrm{O}$ stretching vibration $450-385 \mathrm{~cm}^{-1}$

Here $\mathrm{O}$ is oxygen, $\mathrm{Me}_{\mathrm{O}}$ is metal in the octahedral site and $\mathrm{Me}_{\mathrm{T}}$ in the tetrahedral site. The metal oxygen absorption band (1) and (2) are pronounced for all spinel structures and essentially for ferrites, which are also seen in the samples. For all the samples synthesized by this method two bands are absorbed at 472, 467, 473, $478 \mathrm{~cm}^{-1}$ and 566, 559, 568, $574 \mathrm{~cm}^{-1}$ respectively. IR spectral data of all the ferrite samples are in agreement with the reported value. [10]

Scanning Electron Microscopy (SEM) technique is widely used form of electron microscopy in the field of material science. SEM is an instrument, which is used to observe the morphology of a sample at higher magnification, higher resolution and depth of focus compared to an optical microscope. In SEM an accelerated beam of mono-energetic electrons is focused on the surface of the sample and a small area is scanned by it. Several signals are generated and appropriate ones are collected depending on the mode of its operations. The signal is amplified and made to form a synchronous image on the cathode ray tube, the contrast resulting from the morphological changes and the variation of atomic number over the area probed. [11]

SEM data was obtained for some samples to observe the surface morphology

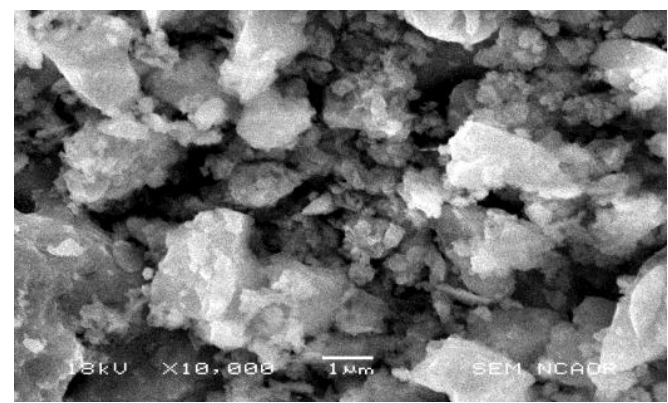

(a)

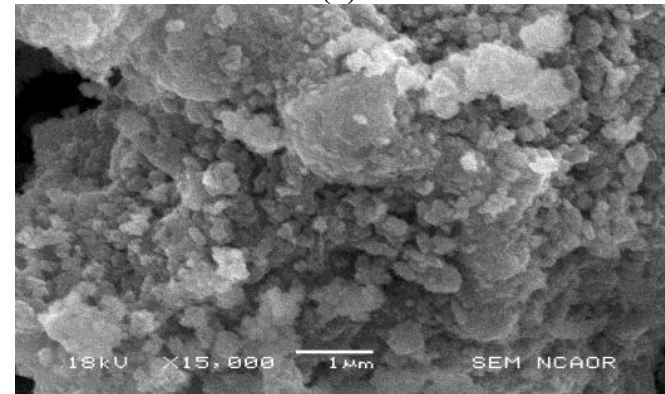

(b)

Figure 3: $\mathrm{SEM}$ micrograph (a) $\mathrm{Ni}_{0.55} \mathrm{Cu}_{0} \mathrm{Zn}_{0.45} \mathrm{Fe}_{2} \mathrm{O}_{4}$ (b) $\mathrm{Ni}_{0.45} \mathrm{Cu}_{0.1} \mathrm{Zn}_{0.45} \mathrm{Fe}_{2} \mathrm{O}_{4}$

It can be seen from the SEM micrograph Fig 3(a) and (b) of $\mathrm{Ni}_{0.55} \mathrm{Cu}_{0} \mathrm{Zn}_{0.45} \mathrm{Fe}_{2} \mathrm{O}_{4}$ and $\mathrm{Ni}_{0.45} \mathrm{Cu}_{0.1} \mathrm{Zn}_{0.45} \mathrm{Fe}_{2} \mathrm{O}_{4}$ that the particles are in nano range and are of high porosity.

Table 2: Variation of particle size

\begin{tabular}{|c|c|}
\hline Concentration of copper & Particle size in nm \\
\hline $\mathrm{Ni}_{0.55} \mathrm{Cu}_{0} \mathrm{Zn}_{0.45} \mathrm{Fe}_{2} \mathrm{O}_{4}$ & 19.41 \\
\hline $\mathrm{Ni}_{0.5} \mathrm{Cu}_{0.05} \mathrm{Zn}_{0.45} \mathrm{Fe}_{2} \mathrm{O}_{4}$ & 37.99 \\
\hline $\mathrm{Ni}_{0.45} \mathrm{Cu}_{0.1} \mathrm{Zn}_{0.45} \mathrm{Fe}_{2} \mathrm{O}_{4}$ & 39.78 \\
\hline $\mathrm{Ni}_{0.4} \mathrm{Cu}_{0.15} \mathrm{Zn}_{0.45} \mathrm{Fe}_{2} \mathrm{O}_{4}$ & 26.11 \\
\hline
\end{tabular}

The variation of the saturation magnetization with $\mathrm{Cu}$ contents for $\mathrm{Cu}-\mathrm{Ni}-\mathrm{Zn}$ ferrite samples of various compositions is given in Table 3. It can be observed that the value for saturation magnetization decreases with increasing $\mathrm{Cu}$ content as reported in literature $[12,13]$. The $\mathrm{Ms}$ is maximum for sample $\mathrm{Ni}_{0.55} \mathrm{Cu}_{0} \mathrm{Zn}_{0.45} \mathrm{Fe}_{2} \mathrm{O}_{4}$ is $77.5 \mathrm{emu} / \mathrm{g}$ and minimum for sample $\mathrm{Ni}_{0.45} \mathrm{Cu}_{0.1} \mathrm{Zn}_{0.45} \mathrm{Fe}_{2} \mathrm{O}_{4}$ is $32.4 \mathrm{emu} / \mathrm{g}$ synthesized by wet chemical method. The hysteresis loss, coercivity and squareness $(\mathrm{Mr} / \mathrm{Ms})$ is found to increase with copper substitution. 


\section{International Journal of Science and Research (IJSR) \\ ISSN (Online): 2319-7064}

Index Copernicus Value (2013): 6.14 | Impact Factor (2014): 5.611

Table 3: Variation of Saturation Magnetization, coercivity and magnetic retentivity

\begin{tabular}{|l|c|c|c|}
\hline \multicolumn{1}{|c|}{ Composition } & $\begin{array}{c}\text { Saturation } \\
\text { Magnetization } \\
(\mathrm{emu} / \mathrm{g})\end{array}$ & $\begin{array}{c}\text { Coercivity } \\
(\mathrm{Hc})\end{array}$ & $\begin{array}{c}\text { Retentivity } \\
\text { (Mr) }\end{array}$ \\
\hline $\mathrm{Ni}_{(0.55-0)} \mathrm{Cu}_{0} \mathrm{Zn}_{0.45} \mathrm{Fe}_{2} \mathrm{O}_{4}$ & 77.5 & 150 & 2.61 \\
\hline $\mathrm{Ni}_{(0.55-0.05)} \mathrm{Cu}_{0.05} \mathrm{Zn}_{0.45} \mathrm{Fe}_{2} \mathrm{O}_{4}$ & 53.44 & 157 & 3.99 \\
\hline $\mathrm{Ni}_{(0.55-0.1)} \mathrm{Cu}_{0.1} \mathrm{Zn}_{0.45} \mathrm{Fe}_{2} \mathrm{O}_{4}$ & 39.3 & 180.5 & 2.66 \\
\hline $\mathrm{Ni}_{(0.55-0.15)} \mathrm{Cu}_{0.15} \mathrm{Zn}_{0.45} \mathrm{Fe}_{2} \mathrm{O}_{4}$ & 32.4 & 201.4 & 2.81 \\
\hline
\end{tabular}

\section{Conclusion}

The present study was carried out to synthesize fine particles $\mathrm{Ni}-\mathrm{Cu}-\mathrm{Zn}$ mixed metal ferrite material with formula $\mathrm{Ni}_{(0.55-}$ ${ }_{x} \mathrm{Cu}_{\mathrm{x}} \mathrm{Zn}_{0.45} \mathrm{Fe}_{2} \mathrm{O}_{4}$ ferrite $(\mathrm{x}=0.0,0.05,0.10$, and 0.15$)$. The samples were prepared by precursor method involving autocombustion and were obtained at low temperature, which were confirmed by different methods of characterization such as IR spectral analysis, XRD and SEM analysis. The lattice constant for the sample are in range of $8.3748 \mathrm{~A}^{0}$ to $8.4080 \mathrm{~A}^{0}$. The average particles size calculated using Scherer formula was in the range of $19.41 \mathrm{~nm}$ to $39.78 \mathrm{~nm}$. Saturation magnetization (Ms) values of sample were found to decrease as copper content increases. The hysteresis losses, coercivity and squareness for the samples are found to increase. Thus this simple wet chemical method, adopting auto combustion for the synthesis, was found to produce nanoparticles $\mathrm{Ni}-\mathrm{Cu}-\mathrm{Zn}$ ferrites materials.

\section{References}

[1] J. bera, P. K.Roy, "Characterization of nanocrystalline $\mathrm{Ni} \mathrm{Zn} \mathrm{Cu}$ ferrite powders synthesized by sol-gel auto Combustion method". Journal of materials processing technology 197. (2008) 279-283.

[2] S. zahi,M. hashim, A. R. Duad, "preparation of Ni Zn $\mathrm{Cu}$ Ferrite particles by sol-gel technique". J. materialLetters 60 . (2006) 2803-2806

[3] E.zhou , Sh. yan, J. Geng, Li. Yin, "preparation of nanocrystalline $\mathrm{Ni} \mathrm{Zn} \mathrm{Cu}$ ferrite particles by sol gel method and magnetic properties". Journal of magnetism and magnetic Materials 277. (2004) 84- 89

[4] Vikas J. Pissurlekar "Study of Influence of Precursor Decomposition on Oxide and Wet Chemical Methods in Synthesis of Ni-Zn Ferrites" International Journal of Science and Research (IJSR) ISSN (Online): 2319-7064 Volume 4 Issue 11, November 2015 1507-1510.

[5] B. Baruwati, R. K. Rana, S. V. Manorama, "Further insights in the conductivity behavior of nano crystalline NiFe2O4", J. Appl.Phys.101 (2007) 014302-014308

[6] S.S. Kumbhar, M. A. Mahadik , V. S. Mohite, K. Y. Rajpure, J. H. Kim, A. V. Moholkar, C. H. Bhosale, J Magn. Magn. Mater.363 (2014) 114-120.

[7] A. Ghasemin, M. Mousavinia Ceramics International 40(2014) 2825-2834.

[8] Z. Yue, L. Li, J. Zhou, H. Zhang, Z.Gui, "Preparation and characterization of $\mathrm{Ni} \mathrm{Cu} \mathrm{Zn}$ ferrite nanocrystalline powders by auto-combustion of nitrate citrate gels". Journal of Materials Science and Engineering B 64. (1999)68-72.
[9] M. A. Gabal, "Magnetic properties of $\mathrm{Ni} \mathrm{Cu} \mathrm{Zn} \mathrm{ferrite}$ nanoparticles synthesized using egg-white". .Material Research Bulletin 45.(2010)589-593.

[10] B. K. Chougule, P. A. Jadhav, R. S. Devan, Y. D. Kolekar, "Structural, electrical and magnetic characterizations of $\mathrm{Ni}-\mathrm{Cu}-\mathrm{Zn}$ ferrite synthesized by citrate precursor method". Journal of Physics and Chemistry of solids 70(2009)396-400.

[11]L. Reimer, ,Scanning Electron: Physics of image formation and microanalysise ${ }^{\text {Se }}$ Springer Publication (1998).

[12] I. Z. Rahman, and T. T. Ahmed, J. Magn. Magn. Mater. 1576, 290 (2005).

[13] J. J. Shrotri, S. D. Kulkarni, C. E. Deshpande, A. Mitra, S. R. Sainkar, P. S. AnilKumar, and S. K. Date, Mat. Chem. Phys. 59, 1 (1999). 